\title{
Trait-mediated indirect interactions in ecological communities
}

\author{
Shunsuke Utsumi $\cdot$ Osamu Kishida $\cdot$ \\ Takayuki Ohgushi
}

Received: 20 February 2009/Accepted: 27 May 2009/Published online: 21 August 2010

(C) The Society of Population Ecology and Springer 2010

Understanding of how trophic linkages make up ecological communities has been one of the most important ecological issues over several decades (Hairston et al. 1960; Paine 1980; Polis and Winemiller 1996; Berlow et al. 2004). An ecological community of interacting species has been conceptualized as a food web in which species are linked through direct trophic interactions between predators and their prey (Polis and Winemiller 1996). Historically, ecologists have been concerned with direct and indirect interactions in which one species changes the density of another species due to consumption (Abrams et al. 1996; Preisser et al. 2005; Werner and Peacor 2006). The consumptive and lethal effects of predators have been commonly viewed as the principal mechanisms regulating prey density and indirectly influencing other species through density-mediated indirect effects (Hairston et al. 1960; Holt 1977; Paine 1980; Carpenter et al. 1985). However, more recently, researchers have recognized that in numerous systems, consumers are important for population and

\section{S. Utsumi $(\bowtie)$}

Department of General Systems Studies, University of Tokyo, 3-8-1 Komaba, Meguro, Tokyo 153-8902, Japan

e-mail: csutsumi@mail.ecc.u-tokyo.ac.jp

\section{S. Utsumi}

Department of Biology, University of Eastern Finland,

Joensuu, Finland

S. Utsumi - T. Ohgushi

Center for Ecological Research, Kyoto University, Otsu, Japan

O. Kishida

Teshio Experimental Forest, Field Science Center for Northern Biosphere, Hokkaido University, Horonobe, Japan community dynamics not only because they eat prey species, but also because they can induce morphological, physiological, behavioral, and life-history changes in the species that they interact with (Karban and Baldwin 1997; Werner and Peacor 2003; Miner et al. 2005; Ohgushi 2005; Ohgushi et al. 2007; Kishida et al. 2010).

Furthermore, such trait changes in species induced by one interacting species can have indirect effects on subsequent interactions with other species. Thus, changes in traits that alter the interaction strength and/or direction can result in various types of trait-mediated indirect effects (Abrams 1995). For example, the strength of trophic relationships between predator and prey animals is affected by trait plasticity, such as inducible defenses of the prey and adaptive foraging by the predators, leading to modified composition of the trophic linkages (Werner and Peacor 2003; Kishida et al. 2009a, b). In herbivore-plant interactions, plants also respond to herbivore damage by phenotypic changes in allelochemistry, physiology, morphology, and phenology (Karban and Baldwin 1997; Ohgushi 2005; Ohgushi et al. 2007). Because these plants provide food and habitat resources to other herbivores, the herbivoreinduced alteration of traits of damaged plants provides the mechanistic basis of trait-mediated indirect interactions among herbivore species (e.g., Utsumi and Ohgushi 2008). Moreover, only recently have microbial ecologists been recognizing the presence of trait-mediated effects in bacteria and phage systems (Miki and Jacquet 2008).

Trait changes can produce widespread and complex trait-mediated indirect effects in ecological communities. There is no doubt that trait changes are important ecological and evolutionary drivers in numerous systems. Given that most organisms cope with variable environments through changes in their traits, consideration of both trophic links and individual traits is critical to enrich 
ecological theory on population and community dynamics. Several studies have shown that behavioral indirect interactions can strongly impact the dynamics of predator-prey interactions and have a similar or stronger impact on prey demography and trophic cascades than density-mediated indirect effects (Schmitz 1998; Preisser et al. 2005). More recently, many researchers, including not only ecologists but also physiologists and molecular biologists, have appreciated induced trait changes and interactions mediated by them (Kessler and Halitschke 2007; Sultan 2007).

Previous studies focusing on trait-mediated effects have developed separately in different research fields, such as animal, plant, and microbial ecology, and much of the research has mainly concerned with animal predator-prey systems. However, we need to draw on the understandings provided by each field and to seek new directions by integrating ideas and perspectives. Finding the general patterns across different systems and principles that organize trait-mediated indirect interactions is likely to be a necessary step in developing this research area. Although researchers often focus on interacting pairs of species in particular system, we know that pair-wise units of direct and/or indirect interactions should be influenced by other interactions with additional interactive units in nature (Daugherty et al. 2007; Kondoh 2008). In this context, Griffin and Thaler (2006) found that behavioral response of the prey (Manduca sexta, tobacco hornworm) against the predator (Podisus maculiventris, stink bug) affected induced resistance of the plant (Solanum ptychanthum, eastern black nightshade) against $M$. sexta. The stink bug induces a behavioral shift in the hornworm, resulting in decreased herbivory by the hornworm caterpillars to the nightshade plant. As a result, the presence of the stink bug decreases herbivore-induced production of defensive chemicals in the plant, which negatively affects survival and growth of the hornworm through predator-induced behavioral change in the hornworm. An integrated view of trait-mediated indirect interactions should contribute to extend beyond a focus on pair-wise interactions and examine ecological consequences of trait-mediated indirect effects on multiple species at multiple spatial and temporal scales.

This special feature, which originated from a symposium held in Fukuoka, Japan, in March 2008, aims to review recent advances in this emerging research field, seek new ideas, and illustrate future directions. It is composed of three overview articles on ecological consequences of induced trait changes for population and community properties in various ecological systems, including animal predator-prey systems, insect-plant systems, and microbial systems. As mentioned, most previous review papers, including the special features in Ecology (e.g., Werner and Peacor 2003; Peckarsky et al.
2008) and the review paper in TREE (Miner et al. 2005), have focused on induced trait changes in predator-prey interactions. Thus, this special feature includes two review articles that address trait-mediated indirect interactions in insect-plant and microbial systems. Finally, one integrative paper covering trait-mediated indirect interactions across tritrophic levels attempts to illustrate future direction.

In the first article in this feature, Craig (2010) addresses how population dynamics of herbivorous insects are regulated by herbivore-induced changes in host-plant traits. His synthesis illustrates that induced plant responses affect subsequent generations of herbivores and feedback loops through induced plant responses govern population dynamics (i.e., resource regulation). He also discusses generality and evolutionary aspects of resource regulation cycles in plant-animal interactions.

In the second paper Miki and Jacquet (2010) broaden the scope of this special feature by examining the less frequently studied aspects of trait-mediated indirect effects in aquatic microbial systems. They argue that trait-mediated indirect interactions are also widespread in aquatic microbial communities and that coexistence of protozoa and viruses is possibly maintained by induced trait changes in their prey (i.e., bacteria). Moreover, they propose a unique idea that induced trait changes in bacteria, occurring not only at the individual level but also at the group level, can mediate microbial interactions.

The third article by Utsumi et al. (2010) newly introduces a concept of linkages among multiple trait-mediated indirect interaction units (TMIUs) toward an integrated understanding of complex networks of indirect interactions, including insect-plant and predator-prey relationships in ecological communities. They review recent advances in studies of trait-mediated indirect effects in plant-associated arthropod communities and explore the mechanisms of linkages among TMIUs (e.g., spatiotemporal chain reactions of TMIUs). Finally, future perspectives in this research field and the hypothesis that linkages among TMIUs contribute to the maintenance of biodiversity are proposed.

This special feature is intended to provide ecologists with insight into trait-based effects in different research fields of population and community ecology. This feature not only reveals profound roles of trait changes in various systems but also illustrates ecological consequences of trait-mediated indirect interactions at different space and time scales. We hope this feature will provide its readers with a useful overview of trait-mediated indirect interactions and encourage research on their population and community consequences by suggesting new ideas and directions for future investigations in this emerging field. 


\section{References}

Abrams PA (1995) Implications of dynamically variable traits for identifying, classifying, and measuring direct and indirect effects in ecological communities. Am Nat 146:112-134

Abrams PA, Menge BA, Mittelbach GG, Spiller D, Yodzis P (1996) The role of indirect effects in food webs. In: Polis GA, Winemiller $\mathrm{KO}$ (eds) Food webs: integration of patterns and dynamics. Chapman \& Hall, New York, pp 371-395

Berlow EL, Neutel A-M, Cohen JE, de Ruiter PC, Ebenman B, Emmerson M, Fox JW, Jansen VAA, Jones JI, Kokkoris GD, Logofet DO, McKane AJ, Montoya JM, Petchey O (2004) Interaction strengths in food webs: issues and opportunities. J Anim Ecol 73:585-598

Carpenter SR, Kitchell JM, Hodgson JR (1985) Cascading trophic interactions and lake productivity. Bioscience 35:634-639

Craig TP (2010) The resource regulation hypothesis and positive feedback loops in plant-herbivore interactions. Popul Ecol. doi: 10.1007/s10144-010-0210-0

Daugherty MP, Harmon JP, Briggs CJ (2007) Trophic supplements to intraguild predation. Oikos 116:662-677

Griffin CAM, Thaler JS (2006) Insect predators affect plant resistance via density- and trait-mediated indirect interactions. Ecol Lett 9:335-343

Hairston NG, Smith FE, Slobodkin LB (1960) Community structure, population control, and competition. Am Nat 94:421-425

Holt RD (1977) Predation, apparent competition, and the structure of prey communities. Theor Popul Biol 12:197-229

Karban R, Baldwin IT (1997) Induced responses to herbivory. The University of Chicago Press, Chicago

Kessler A, Halitschke R (2007) Specificity and complexity: the impact of herbivore-induced plant responses on arthropod community structure. Curr Opin Plant Biol 10:409-414

Kishida O, Trussell GC, Nishimura K (2009a) Top-down effects on antagonistic inducible defense and offense. Ecology 90:12171226

Kishida O, Trussell GC, Nishimura K, Ohgushi T (2009b) Inducible defenses in prey intensify predator cannibalism. Ecology 90:3150 3158

Kishida O, Trussell GC, Mougi A, Nishimura K (2010) Evolutionary ecology of inducible morphological plasticity in predator-prey interaction: toward the practical links with population ecology. Popul Ecol 52:37-46

Kondoh M (2008) Building trophic modules into a persistent food web. Proc Natl Acad Sci USA 105:16631-16635
Miki T, Jacquet S (2008) Complex interactions in the microbial world: unexplored key links between viruses, bacteria, and protozoan grazers in aquatic environments. Aquat Microb Ecol 51:195-208

Miki T, Jacquet S (2010) Indirect interactions in the microbial world: specificity and similarity to plant-insect system. Popul Ecol. doi: 10.1007/s10144-010-0235-4

Miner BG, Sultan SE, Morgan SG, Padilla DK, Relyea RA (2005) Ecological consequences of phenotypic plasticity. Trends Ecol Evol 20:685-692

Ohgushi T (2005) Indirect interaction webs: herbivore-induced effects through trait change in plants. Annu Rev Ecol Evol Syst $36: 81-105$

Ohgushi T, Craig TP, Price PW (2007) Ecological communities: plant mediation in indirect interaction webs. Cambridge University Press, Cambridge

Paine RT (1980) Food webs: linkage, interaction strength, and community infrastructure. J Anim Ecol 49:667-685

Peckarsky BL, Abrams PA, Bolnick DI, Dill LM, Grabowski JH, Luttbeg B, Orrock JL, Peacor SD, Preisser EL, Schmitz OJ, Trussell GC (2008) Revisiting the classics: considering nonconsumptive effects in textbook examples of predator-prey interactions. Ecology 89:2416-2425

Polis GA, Winemiller KO (1996) Food webs: integration of patterns and dynamics. Chapman \& Hall, New York

Preisser EL, Bolnick DI, Benard MF (2005) Scared to death? The effects of intimidation and consumption in predator-prey interactions. Ecology 86:501-509

Schmitz OJ (1998) Direct and indirect effects of predation and predation risk in old field interaction webs. Am Nat 151:327-342

Sultan SE (2007) Development in context: the timely emergence of eco-devo. Trends Ecol Evol 22:575-582

Utsumi S, Ohgushi T (2008) Host plant variation in plant-mediated indirect effects: moth boring-induced susceptibility of willows to a specialist leaf beetle. Ecol Entomol 33:250-260

Utsumi S, Ando Y, Miki T (2010) Linkages among trait-mediated indirect effects: a new framework for the indirect interaction web. Popul Ecol. doi:10.1007/s10144-010-0237-2

Werner EE, Peacor SD (2003) A review of trait-mediated indirect interactions in ecological communities. Ecology 84:1083-1100

Werner EE, Peacor SE (2006) Lethal and nonlethal predator effects on an herbivore guild mediated by system productivity. Ecology $87: 347-361$ 